JURNAL PENDIDIKAN USIA DINI

DOI: https://doi.org/10.21009/JPUD.122

DOI: https://doi.org/10.21009/JPUD.122.01

\title{
PROFIL KESIAPAN SEKOLAH ANAK MEMASUKI SEKOLAH DASAR
}

\author{
Anayanti Rahmawati ${ }^{1}$ \\ Mareyke Maritje Wagey Tairas ${ }^{2}$, Nur Ainy Fardana Nawangsari ${ }^{3}$ \\ Fakultas Psikologi Universitas Airlangga Surabaya \\ E-mail: anayanti_r@staff.uns.ac.id ${ }^{1}$, mareyke.tairas@psikologi.unair.ac.id ${ }^{2}$, \\ nurainy.fardana@psikologi.unair.ac.id ${ }^{3}$
}

\begin{abstract}
ABSTRAK
School readiness is the child's readiness to enter formal school. This term in Indonesia is commonly used to refer to child's readiness to enter elementary school. School readiness needs to be owned by children before entering elementary school so that children can participate in all learning activities properly. This study aims to determine the condition of school readiness owned by children before entering elementary school. Research method used is a survey. Data analysis was carried out descriptively by comparing the mean score of each dimension in school readiness. Results showed that the mean score from highest to lowest in the dimensions of school readiness were academic knowledge dimension, physical wellbeing and motor development dimension, basic thinking skills dimension, self-discipline dimension, social emotional maturity dimension and communication skills dimension. Mean score dimensions in cognitive skills aspect (academic knowledge dimension and basic thinking skills dimension) is higher than mean score in noncognitive skills aspect (self-discipline dimension, social emotional maturity dimension and communication skills dimension). This condition needs to get attention because the realization of school readiness is a combination of all dimensions in school readiness.
\end{abstract}

\section{Keywords: School Readiness, Children, Enter Elementary School}

Kesiapan sekolah merupakan kesiapan anak untuk masuk sekolah formal. Istilah ini di Indonesia lazim digunakan untuk menyebut kesiapan sekolah anak masuk Sekolah Dasar (SD). Kesiapan sekolah perlu dimiliki anak sebelum masuk SD agar anak dapat mengikuti semua kegiatan pembelajaran dengan baik. Penelitian ini bertujuan untuk mengetahui kondisi kesiapan sekolah yang dimiliki anak-anak sebelum masuk SD. Metode penelitian yang digunakan adalah survei. Analisis data dilakukan secara deskriptif dengan membandingkan nilai rata-rata masing-masing dimensi dalam kesiapan sekolah. Hasil penelitian menunjukkan bahwa nilai rata-rata dari tertinggi ke terendah dalam dimensi kesiapan sekolah adalah dimensi pengetahuan akademik, dimensi kesejahteraan fisik dan perkembangan motorik, dimensi kemampuan berpikir dasar, dimensi disiplin diri, dimensi kematangan sosial emosional dan dimensi keterampilan komunikasi. Nilai rata-rata dimensi yang termasuk dalam aspek kemampuan kognitif (dimensi pengetahuan akademik dan dimensi kemampuan berpikir dasar) lebih tinggi daripada nilai rata-rata dimensi yang termasuk dalam aspek kemampuan non kognitif (dimensi disiplin diri, dimensi kematangan sosial emosional dan dimensi keterampilan komunikasi). Kondisi ini perlu mendapat perhatian karena terwujudnya kesiapan sekolah merupakan perpaduan dari semua dimensi dalam kesiapan sekolah.

Kata Kunci: Kesiapan Sekolah, Anak, Masuk Sekolah Dasar 


\section{PENDAHULUAN}

Kesiapan sekolah merupakan kesiapan anak untuk memasuki sekolah. Di Indonesia istilah kesiapan sekolah lazim digunakan untuk merujuk kesiapan anak masuk Sekolah Dasar (SD), sebagai sekolah formal pertama anak. Masuk SD merupakan masa transisi, yaitu periode perpindahan dari Taman Kanak-Kanak (TK) menuju SD. (Arnold, Bartlett, Gowani, \& Merali, 2007) menjelaskan bahwa transisi merupakan periode waktu ketika anak sudah memasuki program prasekolah hingga anak masuk SD. Masa transisi ini bukanlah masa yang mudah bagi anak, karena terdapat berbagai perbedaan tuntutan antara TK dengan SD. Peraturan dan kebijakan di SD sangat berbeda dengan TK, sehingga anak dituntut untuk dapat melakukan berbagai penyesuaian secara cepat dan tepat.

Magdalena (2013) menjelaskan bahwa kondisi di SD berbeda dengan di TK, perbedaan tersebut diantaranya: kegiatan di SD berlangsung lebih lama, tuntutan untuk tidak aktif bergerak dan fokus mendengarkan guru semakin meningkat, meningkatnya kegiatan rutin di sekolah, kesempatan untuk istirahat bermain semakin berkurang, terjadi perubahan pola hubungan kedekatan antara guru-anak serta adanya perubahan dalam hubungan interpersonal dengan teman-teman anak terutama teman di satu kelas (Magdalena, 2013). Selain itu, jika dibandingkan dengan TK, kegiatan di SD kurang berpusat pada anak serta lebih berorientasi pada prestasi akademik (Pianta \& Kraft-Sayre, 1999). Antisipasi menghadapi berbagai perbedaan tersebut menjadikan anak harus sudah melakukan proses persiapan untuk masuk SD di masa transisi.

Proses persiapan ini menurut Sahin dkk (2013) bertujuan untuk menyiapkan anak menuju transisi yang lancar menuju kelas satu SD (Şahİn \& SAK, 2013). Transisi yang lancar dari satu tingkat pendidikan ke tingkat pendidikan berikutnya merupakan komponen penting kesiapan sekolah yang mungkin tidak hanya memprediksi keberhasilan sekolah anak di masa depan, tetapi juga dapat mengatur ritme perilaku mereka dan ketrampilan mengatasi masalah sepanjang hidup mereka (Doherty, 1997). Agar transisi berjalan dengan lancar, anak-anak harus siap untuk sekolah (Arnold et al., 2007). Kesiapan sekolah merupakan kunci utama keberhasilan transisi sekolah (Vernon-feagans \& Blair, 2006).

\section{KAJIAN TEORITIK}

\section{Pengertian Kesiapan Sekolah}

Istilah kesiapan sekolah digunakan untuk menggambarkan persyaratan-persyaratan yang dibutuhkan anak agar dapat membuat transisi yang sukses dari prasekolah menuju sekolah formal (Cuskelly \& 
Detering, 2003). Janus dkk (2007) menyatakan bahwa kesiapan sekolah merupakan kemampuan anak untuk memenuhi tuntutan tugas sekolah(Janus \& Offord, 2007). Snow (2010) menambahkan bahwa kesiapan sekolah merupakan keadaan kompetensi anak pada saat masuk sekolah yang penting untuk kesuksesan di kemudian hari(Snow, 2010).

Kesiapan sekolah cenderung berfokus pada kompetensi sosial dan akademik anak yang dianggap perlu dalam rangka mulai siap sekolah untuk belajar (Mashburn, Pianta, Mashburn, \& Pianta, 2016). Kesiapan sekolah berguna untuk memprediksi prestasi di awal sekolah (Konold, Pianta, Konold, \& Pianta, 2005). Lemelin dkk (2007) menyatakan bahwa kesiapan sekolah berkaitan dengan tingkat perkembangan minimum seorang anak untuk menanggapi tuntutan sekolah melalui kualitas kognitif, sosial dan emosional(Lemelin et al., 2007).

Berdasarkan penjelasan tersebut dapat disimpulkan bahwa kesiapan sekolah merupakan kesiapan anak untuk masuk sekolah, meliputi kompetensi-kompetensi yang diperlukan saat masuk sekolah yang dapat menunjang kesuksesan anak di sekolah.

\section{Dimensi Kesiapan Sekolah}

Kesiapan sekolah anak secara pribadi meliputi: (1) kesehatan dan kemampuan untuk merawat diri sendiri sesuai usia; (2) kemampuan untuk mengatur emosi dan perilaku, berinteraksi secara tepat dengan orang dewasa dan anak-anak, dan mengkomunikasikan kebutuhan dan perasaannya secara efektif; (3) minat dan keterlibatan dengan dunia di sekitarnya, mencakup motivasi belajar, keterampilan motorik, pengetahuan kognitif dan kemampuan menyesuaikan diri dengan tuntutan pengaturan kelas(Piotrkowski, Botsko, \& Matthews, 2006).

Janus dan Offord (2007) menjelaskan bahwa kesiapan sekolah terdiri dari lima domain perkembangan utama yaitu: (1) kesehatan dan kesejahteraan fisik, merujuk pada kesiapan fisik anakanak untuk masuk sekolah, ketrampilan motorik kasar dan halus, kesiapan untuk mengikuti semua aktivitas pembelajaran di sekolah dan kemandirian fisik, (2) kompetensi sosial mencakup kompetensi dan kerja sama bersama dengan orang lain, kemampuan untuk mentaati peraturan, rasa ingin tahu, pendekatan belajar dan pemecahan masalah, (3) kematangan emosional, mencakup perilaku prososial, perilaku, agresi, kurangnya perhatian dan hiperaktif, dan perilaku kecemasan perkembangan bahasa dan kognitif, mengacu pada kemampuan anak untuk menggunakan bahasa dengan benar, aspek kognitif bahasa dan berhitung serta keterampilan membaca dan berhitung dasar, minat 
dan memori, dan keaksaraan yang lebih kompleks (5) keterampilan komunikasi dan pengetahuan umum, mencakup kemampuan anak untuk berkomunikasi secara jelas untuk mengungkapkan kebutuhan dan pemikiran dengan cara yang dapat dimengerti oleh orang dewasa dan anak-anak lain, kemampuan untuk memahami orang lain dan aspek pengetahuan umum(Janus \& Offord, 2007).

Pendapat hampir serupa dinyatakan oleh Fayez dkk (2016) yang menyatakan bahwa kesiapan sekolah terdiri dari enam dimensi yaitu (1) pengetahuan akademik, (2) ketrampilan berpikir dasar, (3) kesejahteraan fisik dan perkembangan motorik, (4) kematangan sosial emosional, (5) disiplin diri dan (6) ketrampilan komunikasi (Fayez et al., 2016).

Berdasarkan pendapat tersebut dapat disimpulkan bahwa kesiapan sekolah terdiri dari beberapa dimensi. Penelitian ini menggunakan enam dimensi kesiapan sekolah yang dikemukakan oleh (Fayez et al., 2016).

\section{Ciri-ciri Anak Siap atau Tidak Siap Sekolah}

Hasil penelitian PACEY (2013) terhadap guru mendapatkan hasil bahwa $65 \%$ guru yang menjadi sampel penelitian menyatakan bahwa anak-anak yang telah memiliki kesiapan sekolah memiliki ciri-ciri antara lain: percaya diri dan senang berada di sekolah selama beberapa jam tanpa melihat orang tua atau pengasuh, memiliki rasa ingin tahu tentang dunia, keinginan untuk belajar serta memiliki keterampilan sosial yang baik. Doherty (1997) menyatakan bahwa anak-anak yang telah siap untuk sekolah memiliki kemungkinan lebih besar untuk mengalami kesuksesan sepanjang hidup karena lebih mampu untuk menyelesaikan sekolah tinggi sehingga dapat mencari pekerjaan yang baik di masa depan serta membuat kontribusi positif bagi masyarakat sebagai warga negara yang produktif (Doherty, 1997).

Sebaliknya, anak-anak yang tidak memiliki kesiapan sekolah sering menunjukkan ciri-ciri negatif, antara lain menunjukkan perilaku bermasalah di dalam kelas, kurang memiliki kemampuan untuk bekerja sama dengan teman maupun guru, kesulitan berkomunikasi terutama untuk menyatakan perasaan dan keinginannya, juga terdapat kecenderungan lebih besar untuk melakukan perilaku negatif seperti agresi fisik, bullying ataupun mengganggu kegiatan temantemannya (Doherty, 1997). Anakanak dengan tingkat kesiapan sekolah lebih rendah pada saat masuk sekolah lebih mungkin untuk mengalami kesulitan di sekolah, karena mengalami masalah yang berhubungan dengan perilaku dan ketrampilan sosial (Connell \& Prinz, 2002) sehingga dapat membuat anak 
mengalami kesulitan dalam akademik dan perilaku di sekolah dibandingkan dengan teman sebaya yang lebih siap sekolah (Konold et al., 2005). Kurangnya kesiapan sekolah merupakan prediksi kuat terhadap kesulitan kerja, kriminalitas, dan gangguan psikologis (Keating \& Hertzman, 1999).

Berdasarkan penjelasan diatas dapat disimpulkan bahwa kesiapan sekolah sangat penting dimiliki anak karena kesiapan sekolah tidak hanya diperlukan demi terwujudnya kesuksesan belajar di sekolah saja, melainkan juga berpengaruh terhadap kesuksesan anak di masa depan. Mengingat pentingnya kesiapan sekolah bagi anak maka penelitian ini dilakukan untuk mengetahui gambaran kesiapan sekolah yang dimiliki anak-anak ketika akan masuk SD dengan harapan agar orangtua dan guru dapat mempersiapkan kesiapan sekolah anak sebelum anak masuk SD.

\section{METODE PENELITIAN}

Metode yang digunakan dalam penelitian ini adalah survei. Alat ukur menggunakan Skala Kesiapan Sekolah, hasil adaptasi skala yang disusun oleh Fayez dkk (2016) yang terdiri dari enam dimensi dengan masing-masing tingkat reliabilitas sebagai berikut: dimensi pengetahuan akademik $\quad(\alpha=0,905), \quad$ dimensi ketrampilan berpikir dasar $(\alpha=0,939)$, dimensi kesejahteraan fisik dan perkembangan motorik $(\alpha=0,894)$, dimensi disiplin diri $(\alpha=0,950)$, dimensi kematangan sosial emosional $(\alpha=0,890)$, dan dimensi ketrampilan komunikasi $(\alpha=0,558)$.

Penelitian ini merupakan penelitian populasi dengan mengambil sampel penelitian seluruh anak TK kelas B yang berada dalam Gugus V kecamatan Wonosegoro, Kabupaten Boyolali, Propinsi Jawa Tengah yaitu anak-anak yang bersekolah di TK Negeri Pembina, TK Aisyiyah Ketoyan, TK Kasih Ibu, TK Masyitoh Bolo dan TK Pertiwi Seworan. Jumlah seluruh sampel penelitian 110 anak.

Penilaian kesiapan sekolah dilakukan secara teacher report dengan menggunakan instrument skala kesiapan sekolah yang diisi oleh guru kelas dengan pertimbangan guru kelas merupakan orang yang paling mengetahui kondisi anak. Sistem penilaian skala menggunakan sistem likert. Analisis data dilakukan secara deskriptif dengan membandingkan nilai rata-rata (mean score) masing-masing dimensi dalam kesiapan sekolah.

Pelaksanaan pengambilan data dilakukan akhir semester kedua tahun pelajaran 2016/2017 karena saat akhir tahun ajaran merupakan kondisi paling tepat untuk mengetahui kondisi kesiapan sekolah anak masuk SD.

\section{HASIL DAN PEMBAHASAN}

Penelitian ini mendapatkan data kondisi kesiapan sekolah yang 
dimiliki anak-anak di Gugus V kecamatan Wonosegoro kabupaten Boyolali. Hasil tersebut kemudian dianalisis dengan menggunakan analisis statistik deskriptif untuk mendapatkan nilai rata-rata masingmasing dimensi dalam kesiapan sekolah. Hasil secara lengkap dapat dilihat pada tabel 1 berikut.

\begin{tabular}{|c|c|c|c|c|c|c|c|}
\hline \multicolumn{8}{|c|}{ Statistics } \\
\hline & & $\begin{array}{l}\text { Pengetahuan } \\
\text { Akademik }\end{array}$ & $\begin{array}{l}\text { Ketrampilan } \\
\text { Berpikir } \\
\text { Dasar }\end{array}$ & $\begin{array}{l}\text { Kematangan } \\
\text { Sosial } \\
\text { Emosional }\end{array}$ & $\begin{array}{l}\text { Kesejahteraan } \\
\text { Fisik Dan } \\
\text { Perkembangan } \\
\text { Motorik }\end{array}$ & $\begin{array}{l}\text { Disiplin } \\
\text { Diri }\end{array}$ & $\begin{array}{l}\text { Ketrampilan } \\
\text { Komunikasi }\end{array}$ \\
\hline \multirow[t]{2}{*}{$\mathrm{N}$} & Valid & 110 & 110 & 110 & 110 & 110 & 110 \\
\hline & Missing & 0 & 0 & 0 & 0 & 0 & 0 \\
\hline \multicolumn{2}{|c|}{ Mean } & 20.7545 & 18.5545 & 17.6000 & 19.2000 & 17.6182 & 15.6636 \\
\hline \multicolumn{2}{|c|}{ Median } & 21.5000 & 19.0000 & 18.0000 & 19.0000 & 17.0000 & 15.0000 \\
\hline \multicolumn{2}{|c|}{ Mode } & 22.00 & 19.00 & 18.00 & 18.00 & 17.00 & 14.00 \\
\hline \multicolumn{2}{|c|}{ Std. Deviation } & 3.12194 & 2.58644 & 2.44274 & 2.47853 & 2.89885 & 1.96426 \\
\hline \multicolumn{2}{|c|}{ Variance } & 9.747 & 6.690 & 5.967 & 6.143 & 8.403 & 3.858 \\
\hline \multicolumn{2}{|c|}{ Range } & 13.00 & 10.00 & 12.00 & 12.00 & 14.00 & 12.00 \\
\hline \multicolumn{2}{|c|}{ Minimum } & 14.00 & 14.00 & 12.00 & 14.00 & 10.00 & 12.00 \\
\hline \multicolumn{2}{|c|}{ Maximum } & 27.00 & 24.00 & 24.00 & 26.00 & 24.00 & 24.00 \\
\hline
\end{tabular}

Tabel 1. Hasil analisis statistik deskriptif

Berdasarkan data pada tabel 1 diketahui nilai rata-rata berdasarkan urutan paling tinggi hingga terendah adalah dimensi pengetahuan akademik, dimensi kesejahteraan fisik dan perkembangan motorik, dimensi ketrampilan berpikir dasar, dimensi disiplin diri, dimensi kematangan sosial emosional dan dimensi ketrampilan komunikasi.

Secara lebih jelas, urutan rangking dimensi-dimensi ini dapat dilihat pada profil kesiapan sekolah anak pada grafik 1 berikut.

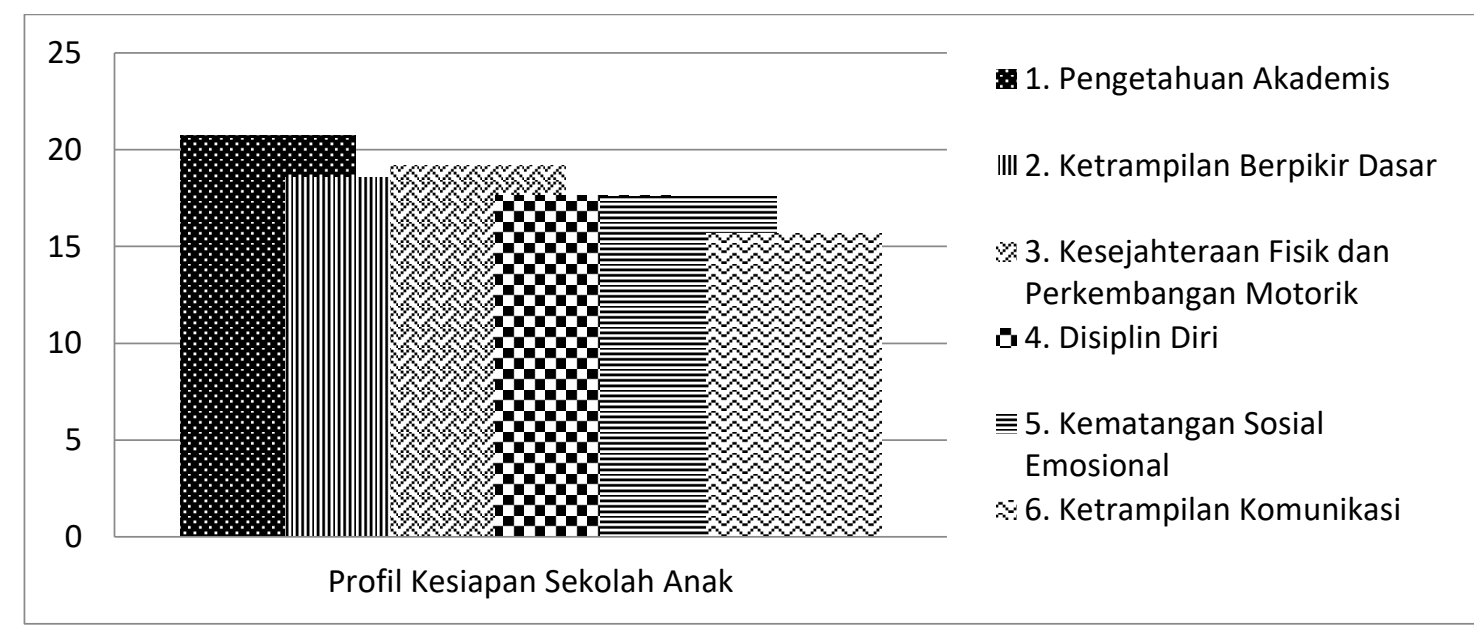

Grafik 1. Profil Kesiapan Sekolah Anak

di Gugus V Kecamatan Wonosegoro Kabupaten Boyolali Tahun 2017 
Hasil survei yang telah dilakukan menunjukkan bahwa dimensi-dimensi dalam profil kesiapan sekolah tersebut dapat dikategorikan dalam aspek kemampuan fisik, kognitif dan non kognitif. Berdasarkan kategorisasi tersebut, dimensi kesejahteraan fisik dan perkembangan motorik yang termasuk dalam aspek kemampuan fisik, menempati rangking kedua dalam profil kesiapan sekolah anak. Kondisi ini menandakan bahwa anakanak dalam keadaan sehat dan sejahtera serta tidak memiliki kelainan dan kendala fisik yang menghambat anak untuk belajar. Selanjutnya, dimensi pengetahuan akademik dan dimensi ketrampilan berpikir dasar yang termasuk dalam aspek kemampuan kognitif, menempati rangking pertama dan kedua dalam profil kesiapan sekolah anak. Kondisi ini menunjukkan bahwa stimulasi pembelajaran yang dilakukan pada kedua dimensi ini sudah sangat baik. Selain itu kondisi ini juga menunjukkan bahwa kemampuan kognitif anak-anak sudah sangat baik. Sedangkan dimensi disiplin diri, dimensi kematangan sosial emosional dan dimensi ketrampilan komunikasi yang termasuk dalam aspek kemampuan non kognitif menempati rangking keempat, kelima dan keenam dalam profil kesiapan sekolah anak. Kondisi ini menunjukkan bahwa kemampuan non kognitif anak-anak masih belum terstimulasi dengan baik.

Jika dicermati pada hasil survei tersebut, terdapat kesenjangan capaian pembelajaran antara aspek kemampuan fisik, kognitif dan non kognitif yang tercermin dalam dimensi-dimensi kesiapan sekolah. Dimensi-dimensi yang tergolong dalam kategori aspek kemampuan non kognitif, memiliki capaian nilai rata-rata yang lebih rendah jika dibandingkan dengan dimensidimensi yang termasuk dalam aspek kemampuan kognitif. Kesenjangan ini perlu mendapatkan perhatian karena merupakan pertanda belum berhasilnya stimulasi pembelajaran pada aspek kemampuan non kognitif pada anak-anak.

Hasil penelitian Nurhayati (2017) terhadap para guru TK di daerah Sleman, Yogyakarta menyatakan bahwa guru cenderung berfokus mengembangkan kompetensi anak dalam keterampilan akademik melalui pembelajaran matematika, membaca dan menulis dengan tujuan untuk mempersiapkan anak-anak agar dapat diterima di SD favorit. Tindakan ini dilakukan guru untuk memenuhi tuntutan orangtua yang menghendaki anak-anak menguasai kompetensi kognitif untuk menghadapi tes seleksi masuk SD favorit. Hasil serupa didapatkan dari penelitian Rahmawati dkk (2018) terhadap guru TK dan orangtua anak yang berpendapat bahwa faktor kognitif dalam kesiapan sekolah 
dianggap lebih penting dari faktor nonkognitif karena faktor kognitif merupakan prasyarat bagi anak untuk dapat diterima di SD favorit.

Meskipun terdapat peraturan yang melarang penggunaan tes kognitif sebagai dasar untuk penerimaan anak masuk SD (Keputusan Menteri Pendidikan Nasional, 2002), namun kenyataan menunjukkan masih banyak SD favorit yang melakukan seleksi penerimaan murid baru dengan dasar tes kognitif. Kondisi ini menyebabkan para guru dan orangtua cenderung lebih mengutamakan kesiapan sekolah dalam bidang kompetensi kognitif.

Kondisi yang terjadi pada hasil survei ini pun demikian, rendahnya capaian nilai rata-rata pada kemampuan non kognitif anak-anak, disebabkan karena guru lebih mengutamakan capaian pembelajaran kemampuan kognitif dibandingkan dengan kemampuan non kognitif karena tuntutan situasi dan kondisi lingkungan serta tuntutan dari para orangtua. Kondisi yang terjadi ini perlu mendapatkan perhatian karena terwujudnya kesiapan sekolah merupakan perpaduan dari semua dimensi yang ada dalam kesiapan sekolah. Jika salah satu dimensi dalam kesiapan sekolah belum tercapai dengan baik, maka kesiapan sekolah yang dimiliki anak pun belum dapat tercapai dengan baik. Kesenjangan capaian nilai rata-rata antara dimensi-dimensi dalam kesiapan sekolah ini perlu diperhatikan lebih lanjut agar anakanak ketika masuk SD telah memiliki kesiapan sekolah yang baik dalam keseluruhan dimensi.

\section{KESIMPULAN}

Kondisi kesiapan sekolah anakanak TK di Gugus V kecamatan Wonosegoro kabupaten Boyolali perlu mendapatkan perhatian karena belum tercapainya secara maksimal dimensi-dimensi dalam kesiapan sekolah. Diperlukan penanganan khusus agar semua dimensi dalam kesiapan sekolah dapat teraih secara optimal karena rendahnya salah satu dimensi dalam kesiapan sekolah akan menghambat terwujudnya kesiapan sekolah secara keseluruhan.

\section{DAFTAR PUSTAKA}

Arnold, C., Bartlett, K., Gowani, S., \& Merali, R. (2007). Is everybody ready? Readiness, transition and continuity: l essons, $r$ eflections and $m$ oving $f$ orward.

Connell, C. M., \& Prinz, R. J. (2002). The Impact of Childcare and Parent Child Interactions on School Readiness and Social Skills Development for Low-Income African American Children, 40(2), 177-193.

Cuskelly, M., \& Detering, N. (2003). Teacher and Student Teacher Perspectives of School Readiness. Australian Journal of Early Childhood, 28 No. 2.

Doherty, G. (1997). Zero to Six The 
Fayez, M., Ahmad, J. F., \& Oliemat, E. (2016). Jordanian Kindergarten and 1st-Grade Teachers ' Beliefs About Child-Based Dimensions of School Readiness Jordanian Kindergarten and 1st-Grade Teachers 'Beliefs About. Journal of Research in Childhood Education, 30(3), 293305.

https://doi.org/10.1080/02568543.2 016.1178195

Janus, M. A., \& Offord, D. R. (2007). Development and Psychometric Properties of the Early Development Instrument (EDI ): A Measure of Children ' s School Readiness *, 39(1), 1-22. https://doi.org/10.1037/cjbs200700 1

Keating, D. P., \& Hertzman, C. (Eds. ). (1999). Developmental health and the wealth of nations. New York: Guilford Press.

Konold, T. R., Pianta, R. C., Konold, T. R., \& Pianta, R. C. (2005). Empirically-Derived , PersonOriented Patterns of School Readiness in Typically-Developing Children: Description and Prediction to First-Grade Achievement TypicallyDeveloping Children: Description and Prediction to First-Grade Achievement, (January 2015), 3741.

https://doi.org/10.1207/s1532480x ads0904

Lemelin, J., Boivin, M., Forget-dubois, N., Dionne, G., Se, J. R., Brendgen, M., ... Pe, D. (2007). The GeneticEnvironmental Etiology of Cognitive School Readiness and Later Academic Achievement in Early Childhood, 78(6), 1855-
Magdalena, S. M. (2013). Social and emotional competence - predictors of school adjustment. Procedia Social and Behavioral Sciences, 76, 29-33. https://doi.org/10.1016/j.sbspro.20 13.04.068

Mashburn, A. J., Pianta, R. C., Mashburn, A. J., \& Pianta, R. C. (2016). Social Relationships and School Readiness and School Readiness, 9289(May). https://doi.org/10.1207/s15566935 eed1701

Nasional, M. P. Penerimaan Siswa ada Taman Kanak-kanak dan Sekolah, Pub. L. No. 051/U/2002 (2002). Indonesia.

Nurhayati, W. (2017). Exploring the understanding and practice of school readiness and transition to school in the Yogyakarta Province in Indonesia.

PACEY. (2013). What Does “ School Ready” Really Mean? Bromley.

Pianta, R. C. ., \& Kraft-Sayre, M. (1999). Parents' Observations about Their Children's Transitions to Kindergarten. Young Children, 54, $47-52$.

Piotrkowski, C. S., Botsko, M., \& Matthews, E. (2006). Parents' and Teachers 'Beliefs About Children' s School Readiness in a High-Need Community, 558(4), 537-558.

Rahmawati, A., Tairas, M. M. W., \& Nawangsari, N. A. F. (2018). Children's School Readiness Based on Teachers' and Parents' Perceptions. International Journal of Pedagogy and Teacher 
Education (IJPTE), 2(1), 201-212.

Şahİn, İ. T., \& SAK, R. (2013). A Comparison of Preschool and First Grade Teachers , Views about School Readiness, 13(3), 17081713.

https://doi.org/10.12738/estp.2013. 3.1665

Snow, K. L. (2010). Early Education and Development Measuring School Readiness: Conceptual and Practical Considerations, (April
2015), $37-41$. https://doi.org/10.1207/s15566935 eed 1701

Vernon-feagans, L., \& Blair, C. (2006). Measurement of School Readiness Measurement of School Readiness, 9289(June).

https://doi.org/10.1207/s15566935 eed 1701 